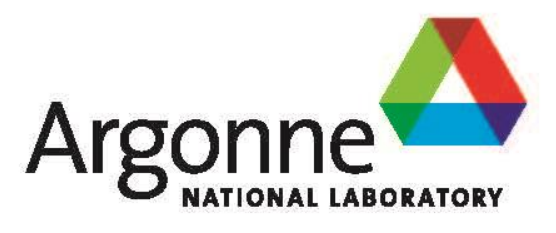

Results of Thermal Test of Metallic Molybdenum Disk Target and Fast-Acting Valve Testing

Nuclear Engineering Division 


\section{About Argonne National Laboratory}

Argonne is a U.S. Department of Energy laboratory managed by UChicago Argonne, LLC under contract DE-AC02-06 CH11357. The Laboratory's main facility is outside Chicago, at 9700 South Cass Avenue, Argonne, Illinois 60439. For information about Argonne and its pioneering science and technology programs, see www.anl.gov.

\section{DOCUMENT AVAILABILITY}

Online Access: U.S. Department of Energy (DOE) reports produced after 1991 and a growing number of pre-1991 documents are available free via DOE's SciTech Connect (http://Www.osti.gov/scitech/)

Reports not in digital format may be purchased by the public from the National Technical Information Service (NTS):

U.S. Department of Commerce

National Technical Information Service

5301 Shawnee Rd

Alexandria, VA 22312

unw.ntis.gov

Phone: (800) 553-NTIS (6847) or (703)

605-6000 Fax: (703) 605-6900

Email: orders@ntis.gov

Reports not in digital format are available to DOE and DOE contractors from the Office of Scientific and Technical Information (OST):

U.S. Department of Energy

Office of Scientific and Technical Information

P.O. Box 62

Oak Ridge, TN 37831-0062

unw.osti.gov

Phone: (865) 576-8401

Fax: (865) 576-5728

Email: reports@osti.gov

\section{Disclaimer}

This report was prepared as an account of work sponsored by an agency of the United States Government. Neither the United States Government nor any agency thereof, nor UChicago Argonne, LLC, nor any of their employees or officers, makes any warranty, express or implied, or assumes any legal liability or responsibility for the accuracy, completeness, or usefulness of any information, apparatus, product, or process disclosed, or represents that its use would not infringe privately owned rights. Reference herein to any specific commercial product, process, or service by trade name, trademark, manufacturer, or otherwise, does not necessarily constitute or imply its endorsement, recommendation, or favoring by the United States Government or any agency thereof. The views and opinions of document authors expressed herein do not necessarily state or reflect those of the United States Government or any agency thereof, Argonne National Laboratory, or UChicago Argonne, LLC. 


\section{Results of Thermal Test of Metallic Molybdenum Disk Target and Fast-Acting Valve Testing}

by

M. Virgo, S. Chemerisov, R. Gromov, C. Jonah, and G.F. Vandegrift Nuclear Engineering Division, Argonne National Laboratory

December 2016 



\section{CONTENTS}

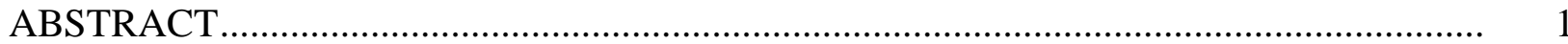

1 THERMAL TEST ....................................................................................................... 2



1.2 Argonne Electron Linac ............................................................................................ 2

1.3 Beam Parameters and History for NorthStar Thermal Test ....................................... 2

1.4 Conclusion ................................................................................................ 5

2 FAST-ACTING VALVE TESTING ........................................................................... 6

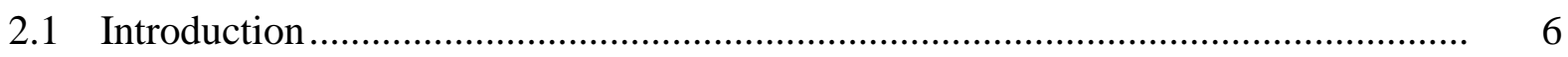

2.1.1 Accelerator Vacuum Systems ..................................................................... 6

2.1.2 Electron Gun Cathodes ............................................................................ 7

2.1.3 Target Window Properties ......................................................................... 7

2.1.4 Expansion of Pressurized Gas into Vacuum................................................. 7

2.2 Experimental Methods .............................................................................................. 9

2.2.1 Fast-Closing Valve................................................................................ 10

2.2.2 Vacuum Measurement ....................................................................... 10

2.2.3 Window Failure ................................................................................ 13

2.2.4 Vacuum System .................................................................................... 14

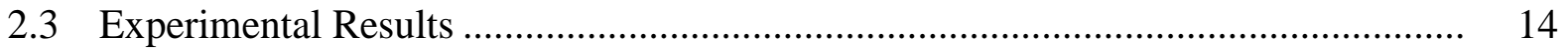

2.4 Conclusions and Recommendations ……………….......................................... 16

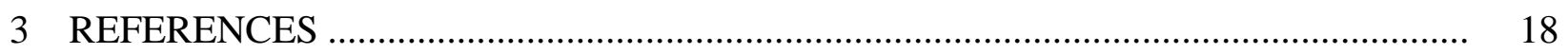

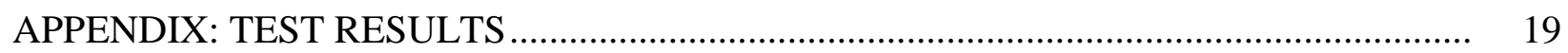

\section{FIGURES}

$1 \quad$ Beam energy spectrum for thermal test. ………................................................... 3

2 Beam power variations during thermal test. Four gradual increases of the beam power were executed.................................................................................................... 3

3 Photograph of thermal test target holder after test and three-month cool-down

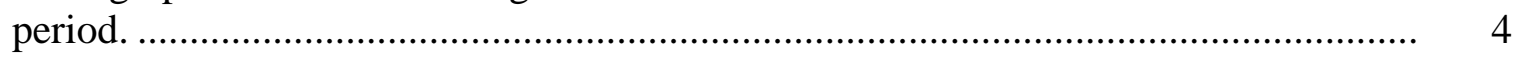

$4 \quad$ Upstream and downstream sections of the fast-closing valve test apparatus. .............. 9

$5 \quad$ Approximate dimensions of the valve test apparatus. .............................................. 10 


\section{FIGURES (Cont.)}

$6 \quad$ Gauges used for final measurements. An ionization gauge, not seen, was installed

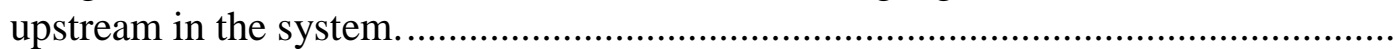

$7 \quad$ Photograph of intact and ruptured discs.................................................................. 13

$8 \quad$ Final pressure measurements downstream of the fast-closing valve............................ 16 


\title{
RESULTS OF THERMAL TEST OF METALLIC MOLYBDENUM DISK TARGET AND FAST-ACTING VALVE TESTING
}

\begin{abstract}
This report describes the irradiation conditions for thermal testing of helium-cooled metallic disk targets that was conducted on March 9, 2016, at the Argonne National Laboratory electron linac. The four disks in this irradiation were pressed and sintered by Oak Ridge National Laboratory from molybdenum metal powder. Two of those disks were instrumented with thermocouples. Also reported are results of testing a fast-acting-valve system, which was designed to protect the accelerator in case of a target-window failure.
\end{abstract}




\section{THERMAL TEST}

\subsection{INTRODUCTION}

Argonne National Laboratory, in cooperation with Los Alamos National Laboratory (LANL), is assisting NorthStar Medical Radioisotopes, LLC, in developing technology for the production of ${ }^{99} \mathrm{Mo}$ via linac irradiation of ${ }^{100} \mathrm{Mo}$. In the past, Argonne in collaboration with LANL conducted a series of thermal and production runs.. In previous thermal tests, we used disks cut from solid rod, which would behave differently from pressed and sintered disks produced from ${ }^{100}$ Mo-enriched material. Specifically, we had a concern about the structural integrity of the pressed and sintered disks due to the high thermal stress induced in the disks by beam heating. Target performance in this test was earlier reported by Woloshun et al. [WOLOSHUN-2016]; the information below supplements that report.

\subsection{ARGONNE ELECTRON LINAC}

Argonne's low energy and high power electron linac was used as a source for an electron beam for the experiments. This machine operates with repetition rate up to $240 \mathrm{~Hz}$ with ultimate beam power up to $110 \mathrm{~W}$ per pulse (maximum average beam power is $25 \mathrm{~kW}$ ). Effective beam energy is in the range from 20 to $45 \mathrm{MeV}$. The highest beam energy is about $50 \mathrm{MeV}$. The DC thermal gun produces electron pulses with amplitude up to $2.0 \mathrm{~A}$ and length from $4 \mathrm{~ns}$ to $6.5 \mu \mathrm{s}$. For the thermal test, we used a 5.5- $\mu$ s pulse length. The RF power for the bunching system and two accelerator structures is provided by two THALES TV2022A klystrons. After acceleration, the beam goes through the beam transport line to the experimental hall and is delivered to the front target window. Steering coils and quadrupole magnets keep the beam in proper shape and position [GROMOV-2015].

\subsection{BEAM PARAMETERS AND HISTORY FOR NORTHSTAR THERMAL TEST}

The beam energy for the thermal test was lowered to $23.0 \pm 0.4 \mathrm{MeV}$ (Figure 1) to increase the power deposition on the window. The beam length was about $5.0 \mu \mathrm{S}$, and the pulse amplitude of the accelerated current was $0.96 \mathrm{~A}$. The accelerated beam pulse charge was about $4.25 \mu \mathrm{C}$, which corresponds to $100 \mathrm{~W}$ of power per pulse. Average beam power is controlled by the accelerator's repetition rate. The thermal test was performed with repetition rate up to $110 \mathrm{~Hz}$. This corresponds to a beam average power of $11.0 \mathrm{~kW}$ and an average beam current of $467 \mu \mathrm{A}$. The thermal test (Figure 2) had some stops, as indicated by the zero power on the target, which correspond to stopping after several minutes of a high power level either due to activation of the interlock system or to measurement of the time response of the data acquisition system. The $11 \mathrm{~kW}$ beam power limit achieved in this test corresponds to maximum safe temperature of the front window. 


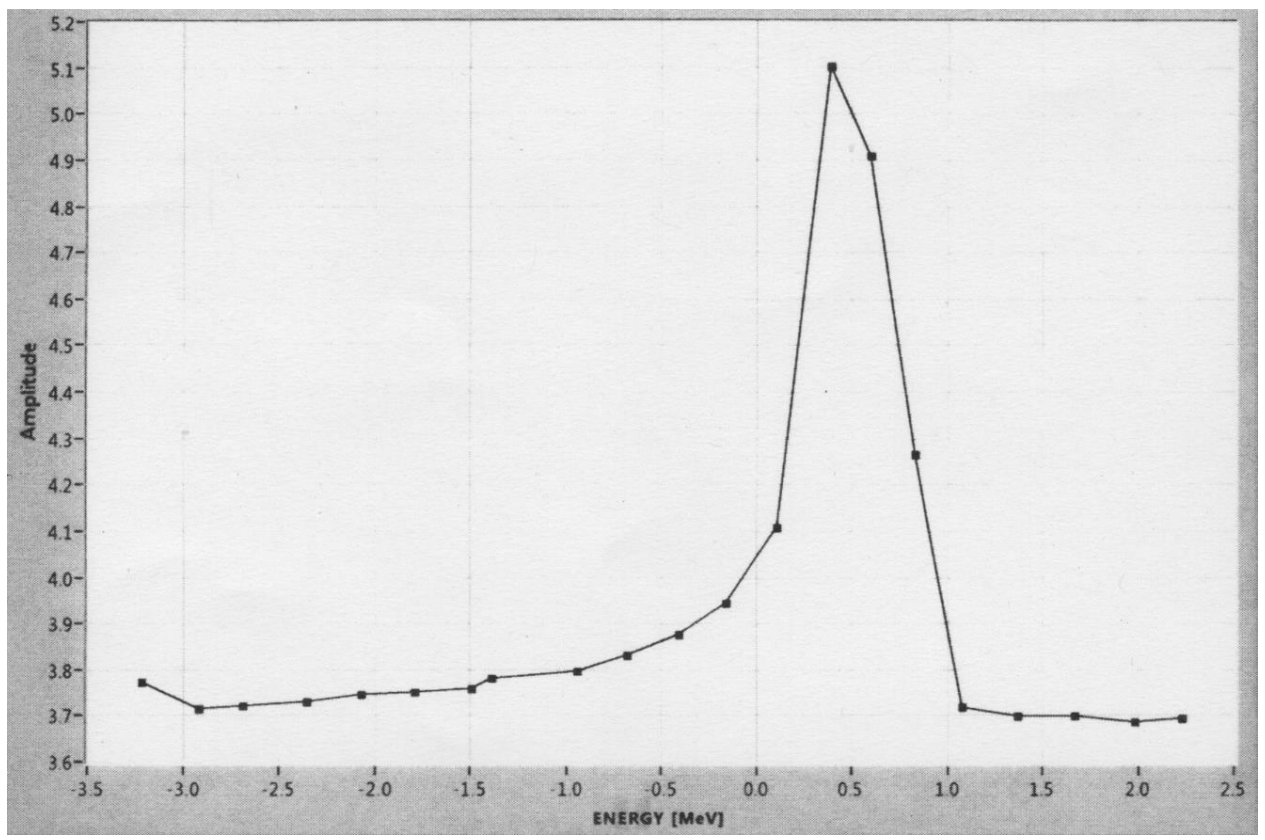

FIGURE 1 Beam energy spectrum for thermal test (zero on the horizontal axis corresponds to $22.5 \mathrm{MeV}$ ).

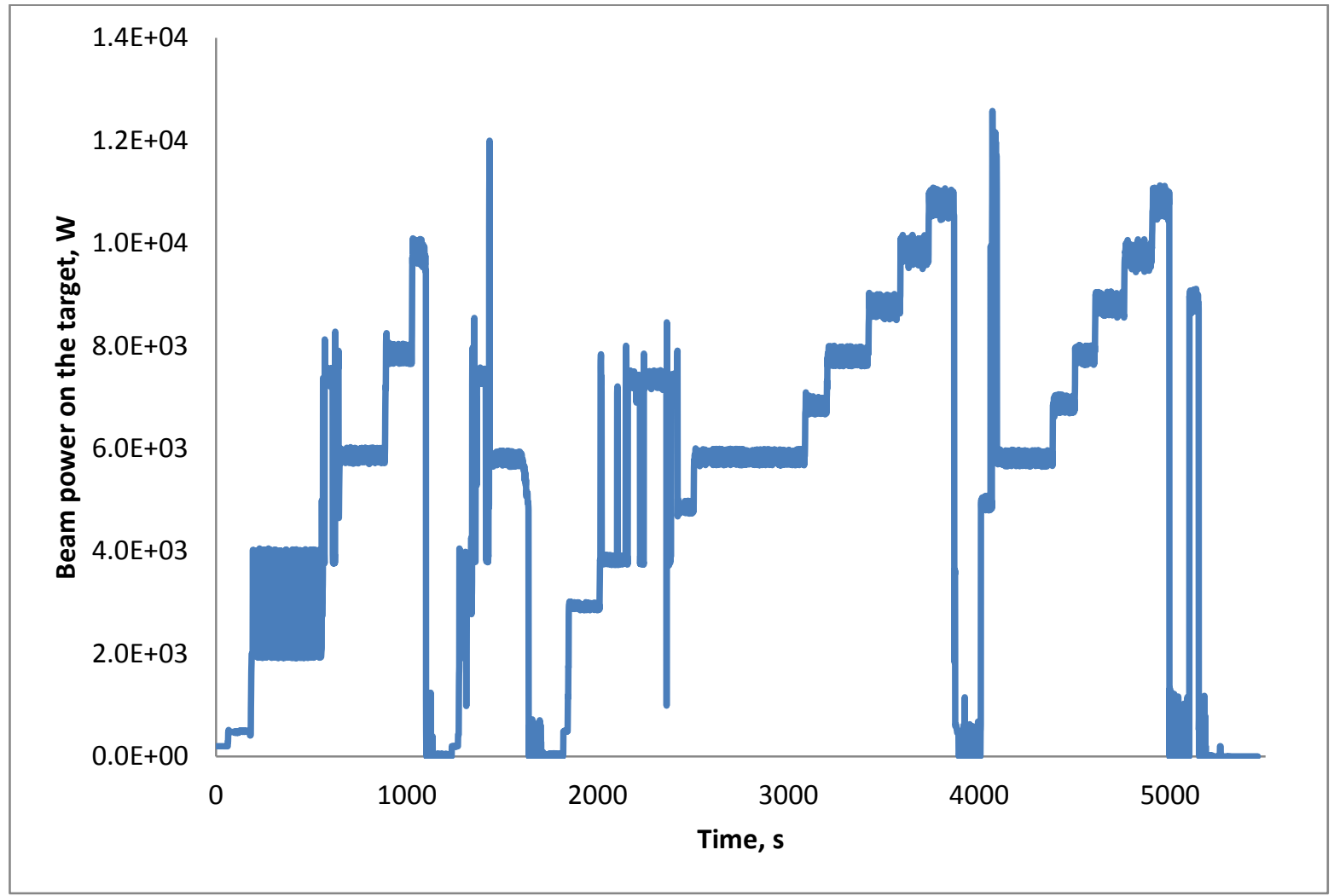

FIGURE 2 Beam power variations during thermal test. Four gradual increases of the beam power were executed. 
The beam-spot size for this test was $3 \mathrm{~mm}$ vertical and $3.5 \mathrm{~mm}$ horizontal full width at half maximum (FWHM). Because the target window had a large scratch and significant oxidation on the surface, measurement of the beam profile directly on the window was not possible. To avoid this problem, we moved the beam at low repetition rate (low power) to the flat part of the target holder and optimized the beam shape there. We did this optimization on both sides of the holder to ensure that the beam profile did not change significantly when we moved the beam.

The thermal test was conducted up to a maximum of $11 \mathrm{~kW}$ beam power because the safety limit for the entrance window temperature was set at $650^{\circ} \mathrm{C}$. After irradiation, we left the target in a helium atmosphere for three months. During this period, the target had significantly cooled down (radiologically), and we examined the beam imprint on the front face of the target. A photograph of the target is shown in Figure 3. The beam imprint on the first disk confirmed the central location of the beam on the target and indicated that the beam was elongated in the horizontal direction. After disassembly of the target holder, all target disks were examined, and no deformation or damage to the sintered disks was observed.

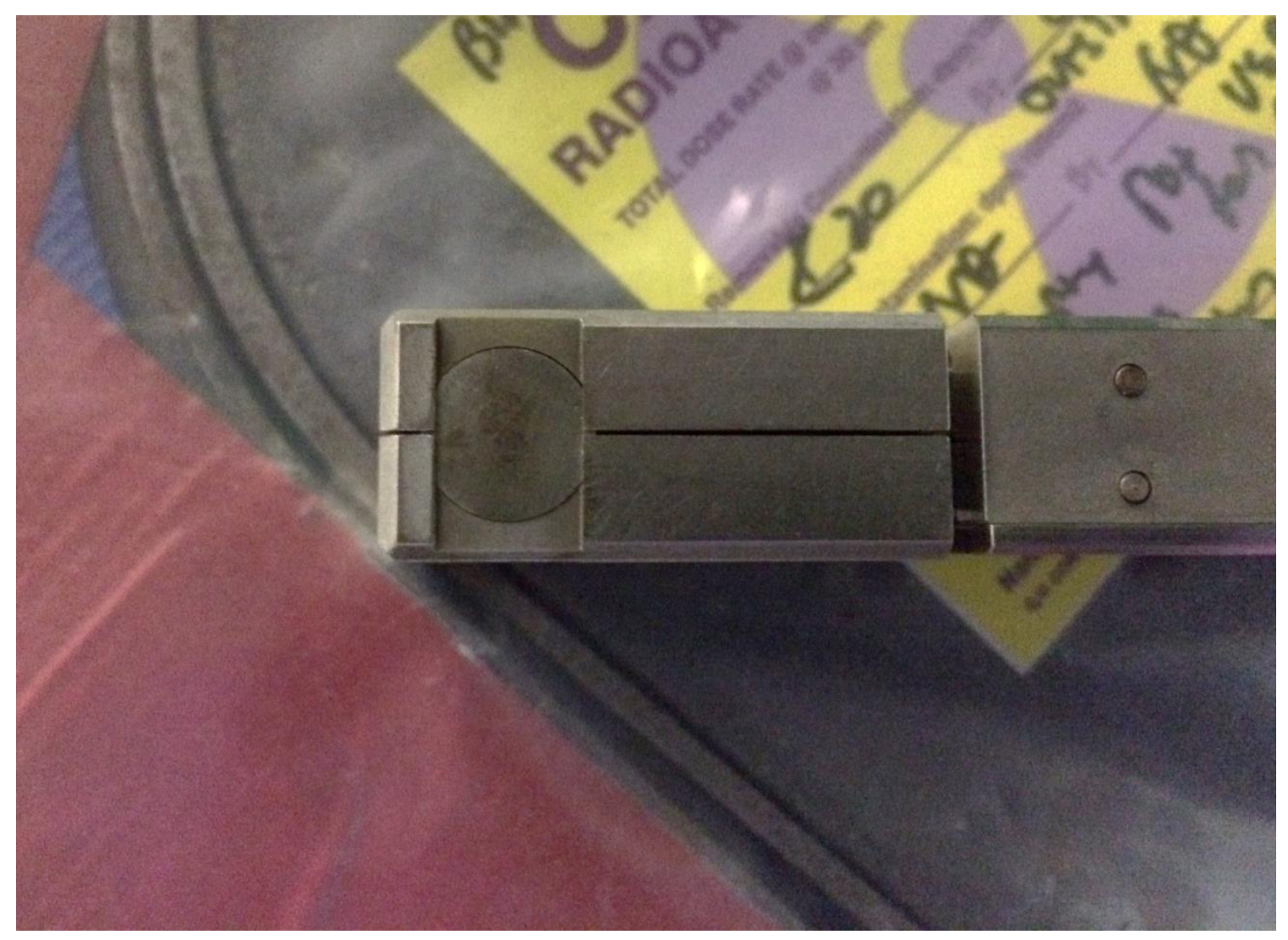

FIGURE 3 Photograph of thermal test target holder after test and three-month cool-down period. 


\subsection{CONCLUSION}

Thermal testing of the molybdenum target with four sintered disks was successfully conducted at the Argonne linac facility. Maximum power on the target was $11 \mathrm{~kW}$, which corresponds to a $650^{\circ} \mathrm{C}$ temperature on the front window. Positioning of the beam on the target was visually verified after completion of the experiment; no deformation or damage to the sintered disks was observed. 


\section{FAST-ACTING VALVE TESTING}

\subsection{INTRODUCTION}

By its nature, accelerator-based production of Mo-99 requires high electron beam power. As a consequence, special precautions must be taken to protect the accelerator components in the event of various failure scenarios. Of particular concern is the target window. The target window is continuously absorbing a fraction of the beam power, and loss of window cooling or adverse changes in beam focusing could cause the window to fail. If this were to occur, an inrush of pressurized helium (the notional cooling medium) would propagate through the accelerator vacuum system. Two accelerator components are particularly susceptible to a potential loss of vacuum conditions. The first is the cathode, which is the electron source in the electron gun. Cathodes are sensitive to chemical contamination, and they are heated to high temperature to release electrons. At elevated temperature, reactive gases reaching the emitting surface can cause permanent damage. The second component is the accelerator cavities themselves, which use large electromagnetic fields to accelerate the electron beam. Increased pressure in these structures may result in electric breakdown, which may again result in permanent damage.

To prevent damage to the accelerator in the event of an equipment failure, we implemented passive and active protection. The primary response is to shut down the accelerator in the event of a problem. This allows the fields in the cavities to dissipate and the cathode to begin to cool. In the case of a window failure, a second, critical step is to isolate the leak from the remainder of the vacuum system. This is accomplished by rapidly closing a gate valve at the first sign of a pressure increase. This report details a set of experiments designed to assess the efficacy of such a vacuum protection system for an accelerator designed for high power irradiation. In the actual accelerator system, the beamline is equipped with a burst disk that relieves the pressure created by high pressure helium gas escaping from the cooling system into the beamline. The burst pressure is set low enough to prevent damage to any beamline components.

\subsubsection{Accelerator Vacuum Systems}

A high $\left(<10^{-3} \mathrm{hPa}\right)$ or ultra-high vacuum $\left(<10^{-7} \mathrm{hPa}\right)$ is required in electron accelerators for a number of reasons, primarily to (1) preserve the cathode, (2) prevent electric breakdown in the accelerating structures, and (3) reduce scattering between the electron beam and gas molecules in the beam tube. Vacuum pumps, primarily diffusion pumps, ion pumps, and turbomolecular (turbo) pumps, are used to maintain a vacuum in the high vacuum or better range. At the Argonne facility, ion pumps are used in the first part of the accelerator, where conditions are more predictable. In the target area, turbo pumps are used because they are able to continue to function if the vacuum conditions deteriorate. 


\subsubsection{Electron Gun Cathodes}

The electron source used in modern industrial accelerators is the dispenser cathode [CRONIN-1981]. These cathodes were developed to meet the requirements for long lifetime in the rugged conditions required, for instance, by klystrons used in radar applications. The dispenser cathode consists of a plug formed from sintered tungsten. The tungsten plug is impregnated with barium oxide and other compounds. When the cathode is heated, those compounds migrate to the cathode surface, reducing the barrier to electron emission and thereby increasing the current emitted at a given temperature. Nominally, these cathodes operate in the temperature range of $700-900^{\circ} \mathrm{C}$.

Dispenser cathodes can only withstand brief exposure to air when they are at room temperature. Exposure to air at elevated temperature causes degradation of the emitting surface and a resulting decrease in current emission capability. Exposure to large quantities of oxygen when the cathode is at operating temperature would rapidly oxidize the tungsten plug, permanently destroying the cathode.

If the target window is cooled by pressurized helium gas, as is planned for the facility envisioned for this program, the initial gas inrush from a target window failure would primarily be composed of helium, and large quantities of other ambient species would be initially displaced by the pressurized helium and then blocked from reaching the front end of the accelerator by the fast-closing valve. In this case, because helium is inert, the consequences to the functioning of the cathode may be mitigated.

\subsubsection{Target Window Properties}

Inconel 718 alloy is used as the beam window of the target designed and fabricated by LANL. The minimum thickness of the window, near the center, is $\sim 100 \mu \mathrm{m}$. The operating pressure of the helium cooling system (also designed by LANL) at the Argonne facility is 280 psig (1.9 MPa).

\subsubsection{Expansion of Pressurized Gas into Vacuum}

In the event of a target window failure, gas flows from the window up to the accelerating cavities and the electron gun through the beam pipe. For steady-state conditions, simple formulas exist for calculating the flow rate through a pipe generated by a given pressure differential. For transient conditions such as these, simulations must be used to obtain accurate results. Here, the basic properties of the flow characteristic of the regimes encountered during the experiments are calculated [MUNSON-2013] to aid in the interpretation of the observed results.

For unobstructed flow, gas begins to propagate from a pressurized region into a void with a velocity that is typically the same order of magnitude as the speed of sound in the gas. The velocity of sound in helium at room temperature is on the order of $1 \mathrm{~km} / \mathrm{s}$. In pipe flow, friction between the gas and the pipe wall becomes a determining factor in the flow rate. As a result of 
these forces, the flow rate is not constant as a function of radius, and the viscosity of the gas begins to affect the flow pattern. When adjacent "layers" of gas slide smoothly across each other, the flow is termed "laminar"; whereas, when they mix, the flow is termed "turbulent." The flow regime determines the reduction in flow relative to ideal (frictionless) conditions. The flow conditions can be quantified by the Reynolds number. For a pipe, $R e=\rho v d / \mu$, where $\rho$ is the density, $\mathrm{v}$ is the mean flow rate, $\mathrm{d}$ is the pipe diameter, and $\mu$ is the viscosity. When the Reynolds number is much lower than 3,000, the flow is laminar; whereas, when it is much higher than 3,000 , the flow is turbulent. For the conditions of this experiment, which are extremely transient and cover a wide range of flow velocity and gas density, it is not possible to define a Reynolds number in the strict sense, but this number can still be useful as an indicator of the flow conditions. From the experiments, it is known that the pressure ranges from as high as 300 psi $(2 \mathrm{MPa}$ ) initially to 1 torr (approximately $100 \mathrm{~Pa}$ ), the diameter of the pipe is $4 \mathrm{~cm}$, and the viscosity of helium gas at room temperature is $20 \mu \mathrm{Pa} \cdot \mathrm{s}$. If it is assumed that the fast-moving helium atoms that can reach the valve before it closes travel at a speed on the order of that of sound (again, $1 \mathrm{~km} / \mathrm{s}$ ), the Reynolds number ranges between $2 \times 10^{7}$ in the high pressure region to 300 in the low pressure region.

A second transition in the gas flow conditions occurs when the density is low enough that collisions between gas molecules and the tube wall begin to supersede intermolecular collisions as the primary phenomenon influencing the flow. This transition is characterized by the Knudsen number, $\mathrm{K} n=\lambda / d$, where $\lambda$ is the mean free path of the gas molecules, and $d$ is the pipe diameter. For an ideal gas, $\mathrm{Kn}=k T / \sqrt{2} \pi r^{2} p L$, where $\mathrm{k}$ is Boltzmann's constant, $\mathrm{T}$ is temperature, $\mathrm{r}$ is the van der Waals radius of the gas molecule, $\mathrm{p}$ is pressure, and $\mathrm{L}$ is pipe length. In pipe flow, the transition occurs when $\mathrm{Kn}$ falls below 0.5 . The hard shell radius of helium is approximately $30 \mathrm{pm}$. The lowest pressure measured during the experiments was approximately $100 \mathrm{~Pa}$, and the corresponding Knudsen number is 0.26 . Though this is slightly below the transition, the overwhelming majority of the expansion process occurs at higher density, when the gas is in the normal flow regime.

Because the diameter of the target window is expected to be on the order of $10 \mathrm{~mm}$, whereas that of the beam pipe is expected to be over one inch, special flow conditions exist at the transition between the target window and the beam pipe. Because of the Venturi effect, there is an upper bound on the mass flow rate through the orifice, a condition termed "choked flow." This condition is certain to occur at the initial instant the window ruptures, when the pressure differential between the cooling gas and the evacuated beam pipe is greatest. For an ideal gas, the flow rate for those conditions is calculated as

$$
\dot{m}=C_{d} A p \sqrt{\frac{m}{k T}} \sqrt{\gamma\left(\frac{2}{\gamma+1}\right)^{\frac{\gamma+1}{\gamma-1}}}
$$

where $C_{d}$ is the coefficient of discharge, a dimensionless quantity less than but on the order of one, determined by the profile of the orifice; $\mathrm{A}$ is the area of the orifice; $\mathrm{m}$ is the mass of the gas molecule $\left(6.67 \times 10^{-27} \mathrm{~kg}\right.$ for helium); and $\gamma$ is the ratio of specific heats (1.66 for helium). For the experiments, the smallest aperture occurred at the outlet of the small gas cylinder preceding the rupture disc. This aperture had a 0.25 in. $(6 \mathrm{~mm})$ diameter. For a starting pressure of $2 \mathrm{MPa}$, 
the initial flow rate is calculated to be $0.06 \mathrm{~kg} / \mathrm{s}$. Given that the volume of the small cylinder is $150 \mathrm{~mL}$, the initial mass of gas in the cylinder is $0.47 \mathrm{~g}$. Therefore, depending on the coefficient of discharge, approximately $7-13 \%$ of the gas in the cylinder is expected to be expelled in the first millisecond after the disc ruptures.

\subsection{EXPERIMENTAL METHODS}

An experiment was designed to evaluate the use of a fast-closing valve to protect the cathode in the event of a target window failure. The aim of the experiment was to approximate the conditions that would be encountered in a production facility. The apparatus designed for the experiments is shown in Figure 4; individual components are described in the following sections.
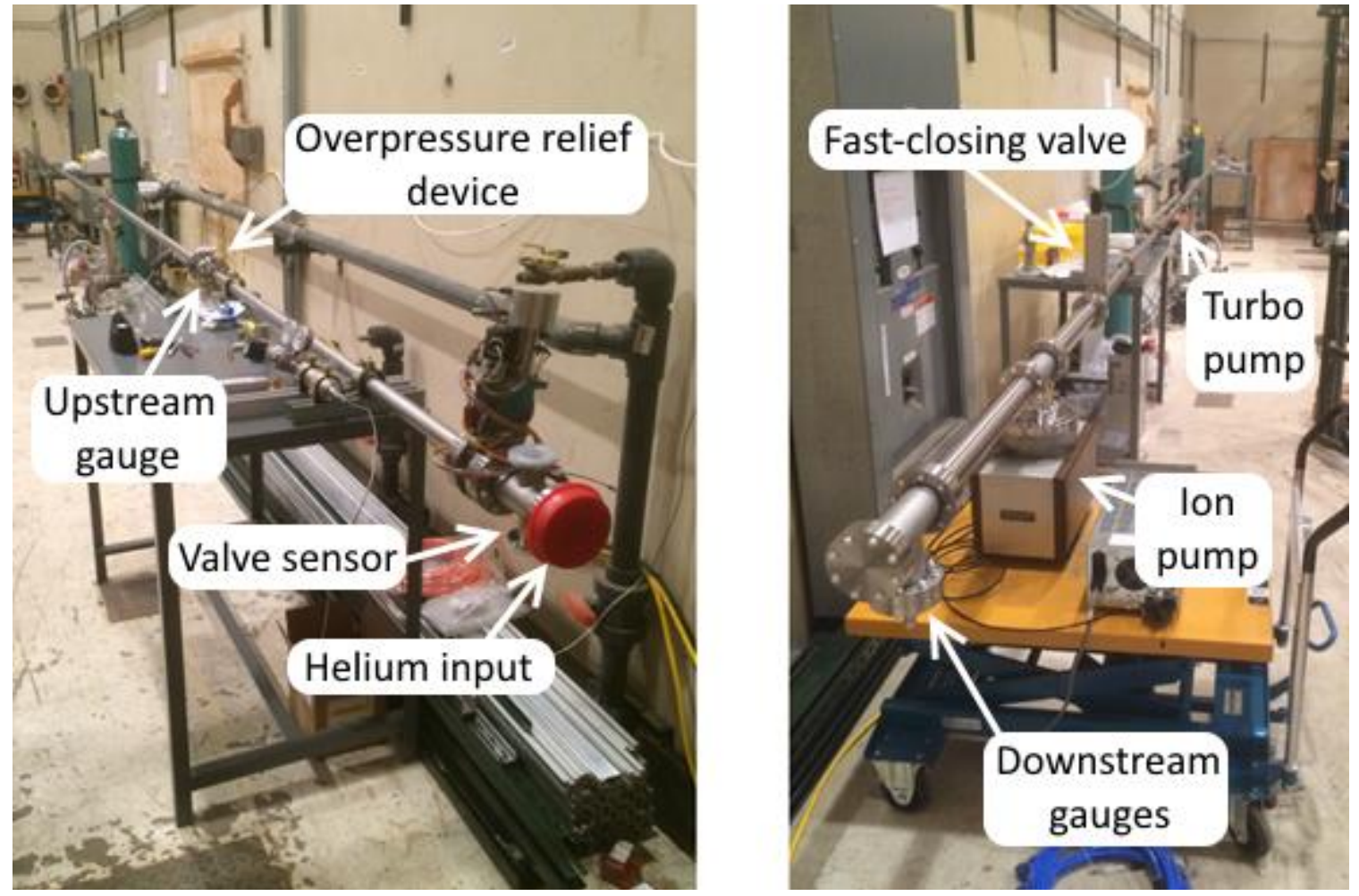

FIGURE 4 Upstream (left) and downstream sections of the fast-closing valve test apparatus. In the upstream area, the location where rupture disc is installed is shown; however, the rupture disc holder is not in place. In the downstream area, an ion gauge is installed in the "downstream gauges" location (bottom flange). Several types of gauges were installed during the course of testing. The ion pump was used during some, but not all, of the experiments. 
Tests were initiated, as described in more detail below, by rupturing a disc at the upstream end of the system. This tripped the valve sensor, closing the fast-closing valve. Measurements were made with a variety of gauges installed at the downstream end of the system. Dimensions of the system are shown in Figure 5.

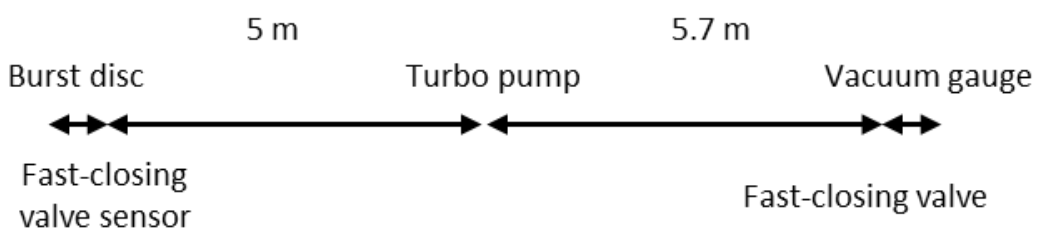

FIGURE 5 Approximate dimensions of the valve test apparatus.

\subsubsection{Fast-Closing Valve}

To the best of our knowledge, the only fast-closing valve system that is widely adopted and commercially available belongs to the VAT 700 series of valves [VATVALVE-2016]. This system is used in our linac and for our testing. It consists of three primary components: transducer, electronics, and valve. The valve used was the VAT series 752 double acting pneumatic gate valve on a DN40 (2.75 in. ConFlat) flange. This valve was coupled to the series 77 control unit. Two transducer options are available, the FV sensor and the HV sensor. The FV sensor is a glow discharge device that trips when the pressure rises above $1 \times 10^{-2} \mathrm{hPa}$ with a response time of $1 \mathrm{~ms}$. The HV sensor is a cold cathode gauge with a trip point adjustable between $10^{-8}$ and $10^{-3} \mathrm{hPa}$ and a response time of $2 \mathrm{~ms}$ (specified at an ambient pressure of one atmosphere). For a large leak, the pressure rise near the location of the leak is almost instantaneous relative to the response time, so the FV sensor was selected to reduce the delay. The specified response time between the time the controller receives a signal and that when a leak tight seal is achieved is no more than $10 \mathrm{~ms}$, so the total closing time from the time the pressure increase reaches the sensor is expected to be less than $11 \mathrm{~ms}$. Once the valve closes, the leak rate through the valve is specified to be less than $1 \times 10^{-9} \mathrm{hPa} \cdot \mathrm{L} / \mathrm{s}$.

The fast-closing valve is not designed to withstand large pressure differentials; its purpose is to catch the rising edge of the pressure increase. In scenarios such as the one considered here, where the inflowing gas is pressurized, additional measures must be taken to protect against the larger pressure increase that may occur over longer time scales. In these tests, and at the linac NorthStar irradiation experiments, a burst disc (MDC Vacuum Products, ASME BDA series, burst pressure $<1 \mathrm{~atm}$ ) was used to prevent over-pressurization.

\subsubsection{Vacuum Measurement}

During the course of testing, pressure measurements from atmospheric pressure to high vacuum were required. Covering this wide range requires several types of gauges. In order from 
low to high vacuum, the types of gauges that were used were mechanical gauges, thermal conductivity gauges, and ionization gauges. The final pressure measurements downstream of the valve were made primarily with mechanical gauges. Several of the measurements were at the very low end of the range of the mechanical gauges that were used, so the thermal conductivity gauges were useful in those cases for establishing a lower bound on the measurements. Ionization gauges were used to measure the initial pressures and to calibrate the thermal conductivity gauges.

The configuration of gauges used to make those measurements is shown in Figure 6.

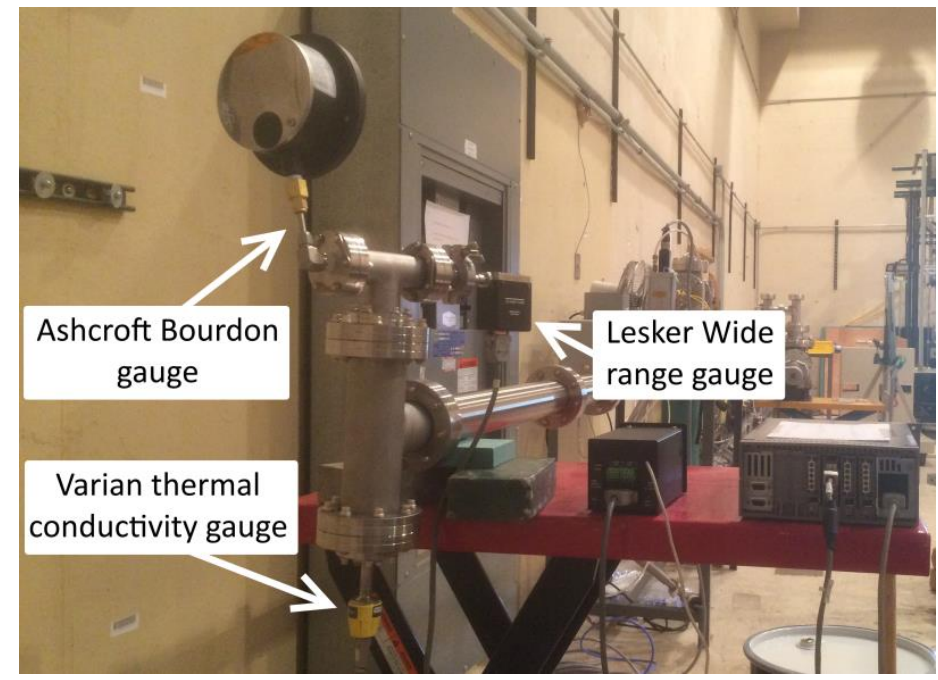

FIGURE 6 Gauges used for final measurements. An ionization gauge, not seen, was installed upstream in the system.

At higher pressure in the range, we used direct pressure measurements, which have the advantage that they are not dependent on the species of gas being measured. For these tests, two types of mechanical gauges were used: a Bourdon gauge, which responds to the deformation of a thin-walled tube as the pressure differential between the inside and outside of the tube is varied, and a diaphragm gauge (capacitance manometer), which measures the change in electrical capacitance between two plates, one of which is a diaphragm separating the volume being measured from a reference volume. Diaphragm gauges are capable of measuring to about $10 \mathrm{hPa}$.

The first gauge that was used in this pressure range was an Ashcroft Type 1082. It is an ASME B40.1 grade 3A Bourdon gauge (accuracy $0.25 \%$ of full scale pressure with calibration, full scale is $30 \mathrm{in.} \mathrm{Hg}$ ) with a $4.5 \mathrm{in}$. dial indicator. Because precision measurements were not required, a full calibration was not performed. However, the gauge was zeroed with the pressure less than $10^{-5}$ torr as read on an ionization gauge. We predict the error resulting from the lack of calibration at atmospheric pressure to be on the order of $2.5 \%$. The dial is marked in tenths of inches of mercury, which corresponds to $3.4 \mathrm{hPa}$. 
The second gauge used in the rough vacuum range was a Kurt J. Lesker Model 902058 Wide Range Gauge with a Model KJL-902056 controller. This gauge module contains two transducers: a diaphragm gauge covering the pressure range $2.7-2000 \mathrm{hPa}$ independent of gas species, and a Pirani gauge covering the pressure range $2.6 \times 10^{-3}$ to $2.7 \mathrm{hPa}$ for air. Effects of gas species on Pirani gauge measurements are discussed below. The accuracy is specified to be $1.3 \times 10^{-3} \mathrm{hPa}$ in the low pressure range and $1.3 \mathrm{hPa}$ in the high pressure range. Although there is a zeroing procedure for the gauge, we chose not to zero the gauge for our experimental conditions because it was borrowed from a third party. Comments on the effects of this are provided below.

In most practical situations, direct measurement techniques are not sufficiently sensitive for determining pressures below $10 \mathrm{hPa}$. The two most commonly encountered gauges used for high vacuum and lower pressures are the thermal conductivity (Pirani or thermocouple) gauge and the ionization gauge. The former measures the rate of cooling of a heated filament due to the interaction of the filament with the gas being measured. Assuming the gauge is calibrated correctly for the ambient conditions, the rate of cooling is proportional to the density of the surrounding gas. Thermal conductivity gauges are capable of measuring pressures from the one atmosphere range down to about $0.1 \mathrm{hPa}$ in air (with decreased accuracy at both extremes of the range). The range, calibration, and accuracy of thermal conductivity gauges are dependent on the species of gas being measured.

In addition to the Pirani gauge incorporated into the Lesker Wide Range Gauge described above, two thermal conductivity gauges were used. The first was a Varian ConvecTorr P-Type gauge, which was used in conjunction with a Varian XGS-600 gauge controller. In air, the range of the gauge is $1.3 \times 10^{-4} \mathrm{hPa}$ to atmospheric pressure. The precision is specified to be " $30 \%$ within a pressure decade." The Varian controller allows the user to specify the gas being measured and internally corrects the pressure readout. The controller has a two-point calibration procedure. First, the vacuum system is evacuated below $10^{-4} \mathrm{hPa}$ and the pressure is zeroed. Then, the gauge is exposed to the atmosphere, and the high range of the gauge is set to the atmospheric pressure. For gases other than air, the manual for the gauge is not clear if the calibration should be carried out in an alternative gas or in air. Both methods were tried, and calibrating the gauge in helium did not appear to give accurate results. Therefore, the gauge was first calibrated in air. The controller was then configured for helium preceding the measurements of helium.

The second thermal conductivity gauge employed was a Granville-Phillips model 275 Convectron Pirani gauge, which was used with a Terranova model 924A Thermocouple Vacuum Gauge Controller purchased from Duniway Stockroom. The Terranova does not offer an internal correction for use with different gas species; it is designed to read correctly with air. However, the manual for the gauge includes tables for converting measurements for several gas species, including helium. The gauge was calibrated using air and vacuum by the same procedure described above for the Varian gauge.

For measurement of pressure in the high vacuum range, ionization gauges were used. These gauges employ a filament to produce electrons, which are accelerated by a voltage applied between the filament and a collector electrode. A fraction of the gas molecules passing through 
the gauge are struck and ionized by the energetic electrons. The resulting ions are swept to the electrodes by the field, adding to the current supplied by the filament. A grid electrode is used to separate the filament current from the total current, allowing the ion current to be determined. The ion current is proportional to the density of gas in the vicinity of the gauge. As for thermal conductivity gauges, ionization gauge measurements are dependent on the properties (physical and electronic) of the gas being measured. For air, ionization gauges are capable of covering the pressure range between $10^{-2} \mathrm{hPa}$ and $10^{-9} \sim 10^{-10} \mathrm{hPa}$.

Because accurate measurement at very low pressure is not critical to the results we report below, it will suffice to note that the gauges used were a Varian-Agilent MBA2-200 ion gauge combined with the Varian XGS-600 controller and an MKS-Granville-Phillips Series 500 cold cathode gauge combined with an onboard controller.

\subsubsection{Window Failure}

To simulate a window failure event for these experiments, we used rupture discs. Rupture discs, or burst discs, are used primarily as safety devices for systems that store or transport pressurized liquid or gas. They consist of a membrane that is designed to rupture at specified pressure (though modified installation procedures were used for these experiments to achieve high vacuum seals, which added uncertainty to the rupture pressure). The rupture discs used in these experiments were purchased from Fike, a commercial provider of overpressure protection equipment. The discs were Fike $\mathrm{P}$ series devices and were fabricated from aluminum. The radius of the area designed to rupture was $0.5 \mathrm{in}$. $(13 \mathrm{~mm})$. The discs were purchased with a compression fitting style holder that trapped the flange of the disc between a flat surface and a small radius. This holder was used in addition to a holder designed in-house that employed a bolt circle to trap the disc between two fittings. The purchased holder incorporated a washer-like component, ostensibly to reduce torsional forces on the disc when tightening the fitting. A second aluminum gasket was used between this component and the body of the fitting to improve the vacuum tightness of the seal. Twenty rupture discs were purchased, 19 of which were used in tests. Half were designed to rupture at $150 \mathrm{psi}(1 \mathrm{MPa})$ while half were designed to rupture at $300 \mathrm{psi}(2 \mathrm{MPa})$. Intact and ruptured discs are shown in the Figure 7.

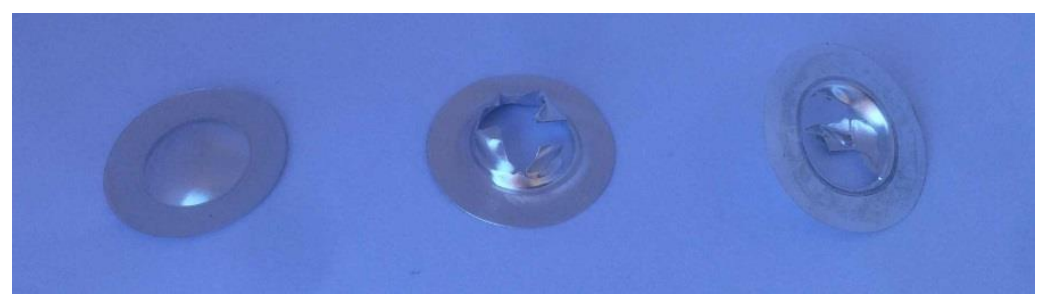

FIGURE 7 Photograph of intact and ruptured discs

To prevent over-pressurization of the vacuum system, a two-step system was used to rupture the disc. First, a $150 \mathrm{~mL}$ secondary cylinder was filled from a standard $250 \mathrm{CF}$ helium 
cylinder to the supply pressure of the primary cylinder. Another $150 \mathrm{~mL}$ cylinder was installed between the secondary cylinder and the rupture disc. The pressure of the third cylinder was controlled by a Fisherbrand 10575129 single-stage regulator. After the secondary cylinder was pressurized, the valve on the primary tank was closed, and the pressure in the third cylinder was increased via the regulator until the disc ruptured. Consequently, the total amount of gas expelled into the vacuum system was limited by the capacity of the two small cylinders.

\subsubsection{Vacuum System}

The test of the fast-closing valve was designed to approximate the conditions of the linac. Details of the geometry are given below. A Sargent Welch turbo pump, backed by an oil-sealed rotary vane pump, was used on the side of the system corresponding to the target area. A Perkin Elmer $60 \mathrm{~L} / \mathrm{s}$ ion pump was used on the side of the system corresponding to the electron gun. Using this configuration, vacuum pressure in the low $10^{-7} \mathrm{hPa}$ scale was reached on the target window side while pressure below $10^{-7} \mathrm{hPa}$ was reached on the electron gun side. Through the course of the experiments, we found that the rise in pressure resulting from the inrush of helium was of a large enough magnitude that it was not necessary for the initial vacuum conditions to be in the $10^{-7} \mathrm{hPa}$ range for an accurate measurement of the final pressure. Therefore, in the later tests, only the turbo pump was used.

\subsection{EXPERIMENTAL RESULTS}

Nineteen tests were carried out. Ten of these tests were conducted at a rupture pressure of $1 \mathrm{MPa}$, and nine were conducted at $2 \mathrm{MPa}$. Many tests were required to configure the experiment and determine the types of gauges that were required for accurate characterization of the resulting conditions. Ultimately, three tests at each rupture pressure were used to quantify the performance of the valve. Conditions of all 19 tests are summarized in the Appendix.

Without the fast-closing valve, the final pressure in the system would be roughly determined by the ratio of the volume of the small helium cylinders to the volume of the whole system. During testing, a valve between the secondary and tertiary cylinders was closed after the disc ruptured, so the pressure would be affected by how fast this valve was closed as well as the rate of flow through the regulator separating the two cylinders. In the upper limit, if both cylinders emptied completely, the initial volume of gas would be approximately $150 \mathrm{~mL}$ at approximately $14 \mathrm{MPa}$, and since the ratio of volumes is approximately 80 , the final pressure would be about $170 \mathrm{kPa}$. If the valve was shut quickly relative to the rate of flow through the regulator, the initial volume would be $150 \mathrm{~mL}$ at 1 or $2 \mathrm{MPa}$, and the final pressure would be approximately 14-28 kPa. The actual pressure would fall somewhere between those limits.

In the first eight tests, the final pressure was measured with a hot filament ion gauge (Varian-Agilent MBA2-200). In these tests, the gauge controller did not respond correctly to the conditions. In all except one case, the controller measured a final pressure in the millitorr scale. For the one exception, the final measured pressure was in the $1 \times 10^{-6} \mathrm{hPa}$ range. Because the readings did not show a dependence on the initial pressure, additional investigations were 
pursued to determine if the measurements were or were not accurate. The next test was characterized with an MKS-Granville-Phillips series 500 cold cathode gauge. This gauge read overpressure conditions at the conclusion of the test. This finding indicates a possible explanation for the inaccuracy of the hot filament gauge - the helium may have cooled the filament, thereby reducing the emission current. It is not clear why the gauge controller did not recognize the reduction in emission current, and once we determined that the gauge was inaccurate, no further attempts were made to investigate this phenomenon.

Given an indication the pressure was higher than could be measured with an ionization gauge, the ionization gauge was removed, and thermal conductivity gauges were installed. Once the gauges were properly calibrated, they also reported overpressure conditions. Based on the gas species conversion tables in the Terranova 924A gauge controller manual, it appears the highest pressure that can be read is $7 \mathrm{hPa}$. We assumed that the Varian-Agilent ConvecTorr gauge has a similar limitation, although explicit documentation could not be found in the manual. The manual for the MKS-Granville-Phillips Series 475 gauge controller, which was not used here but it is the OEM controller for the MKS-Granville-Phillips Convectron 275 gauge, shows a maximum helium measurement pressure of $8 \mathrm{hPa}$ or $11 \mathrm{hPa}$ depending on the specific configuration. The final results obtained during the experiments described here indicate that the final pressure was below $7 \mathrm{hPa}$ in some cases. The reason the thermal conductivity gauges always read overpressurization is not certain. One possible explanation is that thermal conductivity gauges lose accuracy at the upper end of their measurement range, so we may have been seeing an overpressure condition that did not exist. Another possible explanation is the measurement error in the final data, which generally indicated that even the lowest pressures measured were not much below $7 \mathrm{hPa}$.

The thermal conductivity gauges were replaced with mechanical gauges. Results measured on those gauges are reported in Figure 8.

The data indicate that the Ashcroft gauge reads consistently higher than the Lesker gauge. For the $2 \mathrm{MPa}$ rupture discs, where the final pressure was unambiguously above the low end of the range for the Ashcroft gauge, we assumed that the measurements on the Ashcroft gauge are more accurate. The final pressure is, therefore, estimated to be just less than $20 \mathrm{hPa}$. For the $1 \mathrm{MPa}$ discs, the situation is more complicated. The Ashcroft gauge is at the low end of its measurement range, and because the Lesker gauge was not calibrated, the accuracy of those measurements is in doubt. However, the Lesker gauge did not switch to the integrated thermal conductivity gauge, so it can be assumed, as discussed in the previous section, that the pressure is not much lower than $7 \mathrm{hPa}$. Also, when the pressure exceeds $7 \mathrm{hPa}$, the Ashcroft gauge is expected to provide consistent readings. Therefore, we estimated the final pressure for the $1 \mathrm{MPa}$ disc tests to be $7-14 \mathrm{hPa}$. 


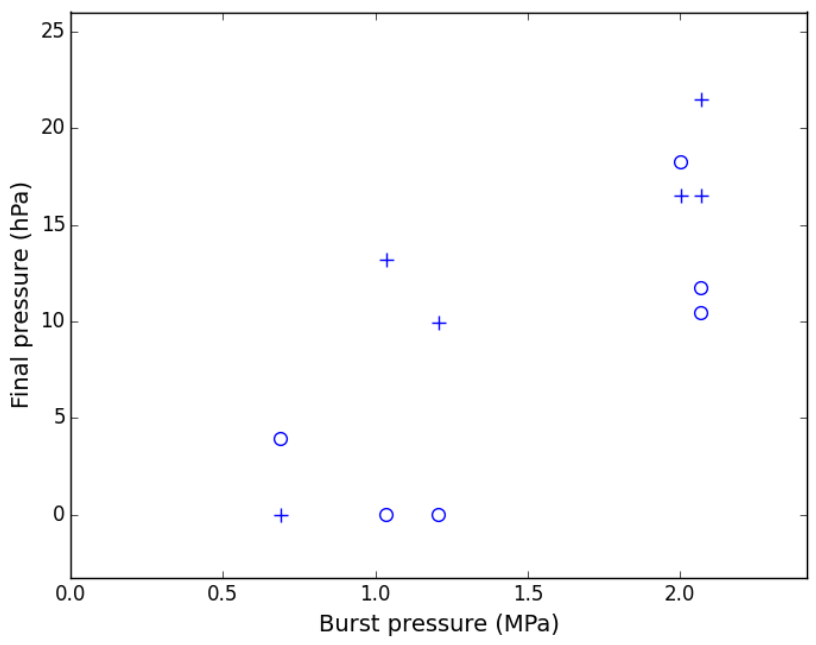

FIGURE 8 Final pressure measurements downstream of the fast-closing valve. Circles represent measurements recorded on the Kurt Lesker 902058 Wide Range Gauge while plus signs were recorded on the Ashcroft 1082 Bourdon Gauge

\subsection{CONCLUSIONS AND RECOMMENDATIONS}

The clear outcome of this investigation is that the conventional technology used for protecting accelerator vacuum systems does not function within normal operating parameters in the context of a system designed for high power irradiation. Specifically, the use of pressurized helium as a cooling medium for the target window, required because of the high thermal load, creates a twofold challenge: first, helium is a lightweight and therefore a fast-moving gas, and second, elevated gas pressure accelerates the rate of flow through the vacuum pipe. This is in contrast to a typical accelerator were the ambient gas is air at atmospheric pressure. A mitigating factor for the high power system is the use of helium, as an inert gas may protect accelerator components even in the event of a pressure rise following a window failure. Typically, the carbon- and oxygen-containing molecules in air are most damaging to sensitive equipment such as the cathode.

To fully develop the production technology, further study is recommended. From this experience, the most cost-effective approach appears to be to investigate the effect of helium gas on the accelerator components. If it is determined that a given level of helium exposure is tolerated by the equipment, the system can then be designed to limit exposure to those levels. Steps could be taken to limit both the amount of exposure by, for instance, considering methods of restricting the flow, and the duration of the exposure by implementing adequate pumping. With precautious such as these supplementing the use of interlocks and valves, a suitable solution should be attainable. 
Several future tasks are proposed. First, the effect of helium on dispenser cathodes should be studied. Small cathodes should be installed in a vacuum chamber, and the emission should be characterized before and after exposure to controlled doses of helium. Second, RF breakdown in accelerator cavities as a function of helium pressure should be considered. Further study with simulation or experiment should be conducted if it is determined to be warranted. Third, once appropriate precautions have been determined, strong consideration should be given to performing in-situ studies of window rupture. By understanding the exact failure mode of the target windows, it will be possible to determine actual instead of estimated leak rates. Finally, once data from the above tests and investigations are complete, two- or three-dimensional modeling of helium flow through the accelerator should be conducted with that data. 


\section{REFERENCES}

[CRONIN-1981] J. L. Cronin, “Modern dispenser cathodes," IEEE Proc. I - Solid-State and Electron Devices 128, 19 (1981).

[GRONOV-2015] R. Gromov, K. Alford, D. Brown, S. Chemerisov, S. Forknall, J. Gardner, L. Hafenrichter, C. D. Jonah, D. Macrillo, R. Tafoya, K. Wesolowski, and A. Zulpo, "Low energy accelerator facility upgrade and test," Proceedings of $12^{\text {th }}$ International Topical Meeting on the Nuclear Application of Accelerators, November 10-13, 2015, Washington, DC.

[MUNSON-2013] B.R. Munson, A. P. Rothmayer, T. H. Okiishi, W. W. Huebsch, Fundamentals of Fluid Mechanics, John Wiley \& Sons, Inc., Hoboken, NJ (2013).

[VATVALVE] VAT, "Series 752: Fast closing valve linear actuator type," http://www.vatvalve.com/business/valves/catalog/F/752_1_V (2016).

[WOLOSHUN-2016] K. Woloshun, G. Dale, E. Olivas, F. Romero, D. Dalmas, S. Chemerisov, R. Gromov, and R. Lowden, Thermal Test on Target with Pressed Disks, Los Alamos National Laboratory Report LA-UR-16-2211 (2016). 


\section{APPENDIX: TEST RESULTS}

\begin{tabular}{|c|c|c|c|}
\hline Test & $\begin{array}{c}\text { Rupture } \\
\text { pressure (psi) }{ }^{1}\end{array}$ & Gauges & Comments \\
\hline 1 & 300 & MBA2-200 2 & Incomplete test \\
\hline 2 & 150 & MBA2-200 & FCV N2 pressure increased to $70 \mathrm{psi}$ \\
\hline 3 & $150(180)$ & MBA2-200 & Alternative rupture disc holder \\
\hline 4 & $300(250)$ & MBA2-200 & Alternative rupture disc holder \\
\hline 5 & 150 & MBA2-200 & \\
\hline 6 & 300 & MBA2-200 & \\
\hline 7 & 150 & MBA2-200 & \\
\hline 8 & 300 & MBA2-200 & \\
\hline 9 & $150(170)$ & Series $500^{3}$ & Gauge read overpressure at conclusion of test \\
\hline 10 & 300 & $\begin{array}{l}\text { MBA2-200 } \\
\text { ConvecTorr }\end{array}$ & ConvecTorr calibration uncertain \\
\hline 11 & 150 & ConvecTorr & Calibration uncertain \\
\hline 12 & 300 & ConvecTorr & Calibration uncertain, gauge reads high at test conclusion \\
\hline 13 & 150 & $\begin{array}{l}\text { ConvecTorr } \\
\text { Convectron } 275^{5}\end{array}$ & $\begin{array}{l}\text { ConvecTorr gauge did not respond } \\
\text { Convectron gauge reads high }\end{array}$ \\
\hline 14 & $300(290)$ & $\begin{array}{l}902058 \mathrm{WRG}^{6} \\
1082 \text { Test Gauge }\end{array}$ & $\begin{array}{l}\mathrm{P}(\mathrm{WRG})=14 \text { torr } \\
\mathrm{P}(1082)=0.5 \text { in. } \mathrm{Hg}\end{array}$ \\
\hline 15 & $150(100)$ & $\begin{array}{l}902058 \text { WRG } \\
1082 \text { Test Gauge }\end{array}$ & $\begin{array}{l}\mathrm{P}(\mathrm{WRG})=3 \text { torr } \\
\mathrm{P}(1082)=0 \text { in. } \mathrm{Hg}\end{array}$ \\
\hline 16 & 300 & $\begin{array}{l}902058 \text { WRG } \\
1082 \text { Test Gauge }\end{array}$ & $\begin{array}{l}\mathrm{P}(\mathrm{WRG})=9 \text { torr } \\
\mathrm{P}(1082)=0.5 \text { in. } \mathrm{Hg}\end{array}$ \\
\hline 17 & $150(175)$ & $\begin{array}{l}902058 \text { WRG } \\
1082 \text { Test Gauge }\end{array}$ & $\begin{array}{l}\mathrm{P}(\mathrm{WRG})=0 \text { torr } \\
\mathrm{P}(1082)=0.3 \text { in. } \mathrm{Hg}\end{array}$ \\
\hline 18 & 300 & $\begin{array}{l}902058 \text { WRG } \\
1082 \text { Test Gauge }\end{array}$ & $\begin{array}{l}\mathrm{P}(\mathrm{WRG})=8 \text { torr } \\
\mathrm{P}(1082)=0.65 \text { in. } \mathrm{Hg}\end{array}$ \\
\hline 19 & 150 & $\begin{array}{l}902058 \text { WRG } \\
1082 \text { Test Gauge }\end{array}$ & $\begin{array}{l}\mathrm{P}(\mathrm{WRG})=0 \text { torr } \\
\mathrm{P}(1082)=0.4 \text { in. } \mathrm{Hg}\end{array}$ \\
\hline
\end{tabular}

1. Actual rupture pressure shown in parenthesis if significantly different from nominal

2. Varian-Agilent MBA2-200 hot filament ion gauge

3. MKS-Granville-Phillips Series 500 cold cathode gauge module

4. Varian-Agilent ConvecTorr P-Type thermal gauge

5. Granville-Phillips Convectron 275 Pirani gauge

6. Kurt Lesker model 902058 wide range gauge

7. Ashcroft 1082 test gauge 
This page is intentionally left blank. 



\section{Argonne}

\section{Nuclear Engineering Division}

Argonne National Laboratory

9700 South Cass Avenue, Bldg. 208

Argonne, IL 60439-4854

www.anl.gov

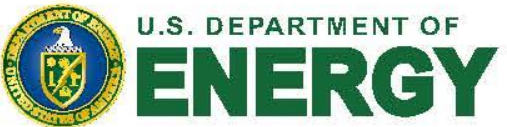

Argonne National Laboratory is a U.S. Department of Energy

laboratory managed by UChicago Argonne, LLC 